\title{
Toxicity of the Combustion Products \\ from a Flexible Polyurethane Foam \\ and a Polyester Fabric Evaluated \\ Separately and Together by the NBS \\ Toxicity Test Method
}

\author{
BARBARA C. LEVIN, MAYA PAABO, CHERYL S. BAILEY, \\ and STEVEN E. HARRIS \\ Center for Fire Research \\ National Bureau of Standards \\ Gaithersburg, Maryland 20899, USA
}

\section{ABSTRACT}

Representative specimens of two materials, a flexible polyurethane foam and a polyester, were thermally decomposed separately and together in order to compare the toxicological effects of the combustion products from the combined materials with those from the single homogeneous materials. Gas concentrations $\left(\mathrm{CO}, \mathrm{CO}_{2}\right.$, $\mathrm{O}_{2}$ and $\mathrm{HCN}$ ), blood carboxyhemoglobin, and $\mathrm{LC}_{50}$ values (the concentration of material necessary to kill $50 \%$ of the test animals (Fischer 344 male rats) during a 30 minute exposure and a 14 day post-exposure observation period] were determined for the separate and combined materials under both flaming and non-flaming conditions. The results of the combined experiments indicated that under nonflaming conditions, both materials contributed in an additive manner to the concentration of the combustion products. However, under flaming conditions, the generation of $\mathrm{HCN}$ and $\mathrm{CO}$ is greater than that predicted from the addition of the maximum amounts produced by the materials separately.

\section{INTRODUCTION}

In the industrialized world, the United States is second only to Canada in the number of fire deaths per capita [1]. The fire scenario which produces the most fire deaths in the U.S. begins with an inadvertently dropped cigarette in an upholstered piece of furniture. Since the majority of commercially available upholstered furniture today contains some formulation of flexible polyurethane foam as a filling material and a covering fabric which is either a cellulosic or a thermoplastic such as polyester, these two materials were chosen for this study. Many smal1-scale laboratory studies have examined the toxicity of the combustion products from flexible polyurethane foams [2] or polyesters [3]. There have also been numerous large-scale room burns of chairs, multiple materials, or composite materials which included these materials. Alarie et al. compared the toxicity of individual materials (determined in small-scale tests) with the toxicity of multiple combined materials (determined in large-scale chair burns) [4]. However, the objective of their study was to compare the toxicity of the major components of the chairs (flexible polyurethane foam, polyester, and

This paper is a contribution of the National Bureau of Standards and not subject to copyright. 
cotton fiber) with their individual toxicity in smal1-scale tests. They did not study the toxicity of the combined components in the small-scale tests.

This study was designed to examine and to compare the toxicological effects from the combustion products of a flexible polyurethane foam and a polyester fabric in order to determine the contribution of the combustion products from each material to the overall toxicity of the mixture. Two separate aspects of this problem were considered: (1) Would the toxicity be affected merely because the increased mass of the combined materials increase the concentrations of the pyrolysis or combustion products or does some unexpected toxicological interaction occur? (2) Would the types or yields of toxicants be affected?

\section{MATERIALS AND METHODS}

The materials studied, polyester fabric and a flexible polyurethane foam, were generically classified, i.e., the specific chemical formulations were unknown. Both the polyester upholstery fabric ( $100 \%$ polyester, scoured and dyed dark blue) and the flexible polyurethane foam were obtained from the Consumer Product Safety Commission, Washington, DC 20207. The results of a previous toxicological study on this polyurethane foam, designated CPSC 非13, have been published [5].

The acute inhalation toxicity of the combustion products from these materials was evaluated according to the NBS Toxicity Test Method [6]. Each material was examined at $25^{\circ} \mathrm{C}$ above and below its autoignition temperature (Tables $1 \& 2$ ). In addition, polyester was tested at the non-flaming temperature of the polyurethane foam $\left(375^{\circ} \mathrm{C}\right)$, and the flexible polyurethane foam was examined at the flaming temperature of the polyester $\left(525^{\circ} \mathrm{C}\right)$. Combinations of the two materials were thermally decomposed in the cup furnace at a non-flaming temperature of $375^{\circ} \mathrm{C}$ (which was the highest possible non-flaming temperature, since the polyurethane foam would flame at higher temperatures) and a flaming temperature of $525^{\circ} \mathrm{C}$ (the temperature at which both the polyurethane and polyester would undergo flaming combustion, if tested separately). In all cases, the amount of material consumed was determined by weighing the residue.

Carbon monoxide ( $\mathrm{CO})$ and carbon dioxide $\left(\mathrm{CO}_{2}\right)$ were measured continuously by nondispersive infrared spectroscopy. Oxygen concentrations were measured continuously by a galvanic cell or a paramagnetic analyzer. The HCN generated from the polyurethane foam was sampled with a gas-tight syringe approximately every three minutes and analyzed with a gas chromatograph equipped with a thermionic detector $[7]$.

Fischer 344 male rats, weighing 200-300 grams, were obtained from the Harlan Sprague-Dawley Company (Walkersville, Maryland) or Taconic Farms (Germantown, New York) and were allowed to acclimate to our laboratory conditions for 10 days prior to experimentation. Animal care and maintenance were performed in accordance with the procedures outlined in the National Institutes of Health's "Guide for the Care and Use of Laboratory Animals" [8].

Six animals were exposed in the head-only mode in each experiment. Exposures were for 30 minutes, during which blood for carboxyhemoglobin (COHb) analysis was taken at 0 time, approximately 15 minutes and just before the end of the experiment from cannulated animals (one or two animals per exposure were surgically prepared with a femoral arterial cannulae 24 hours before experiments [9]). The number of animals that died at each mass loading of material was plotted to produce a concentration-response curve from which an $\mathrm{LC}_{50}$ value was calculated [10]. The $\mathrm{LC}_{50}$, in this case, is defined as the mass loading of material per 
Table 1

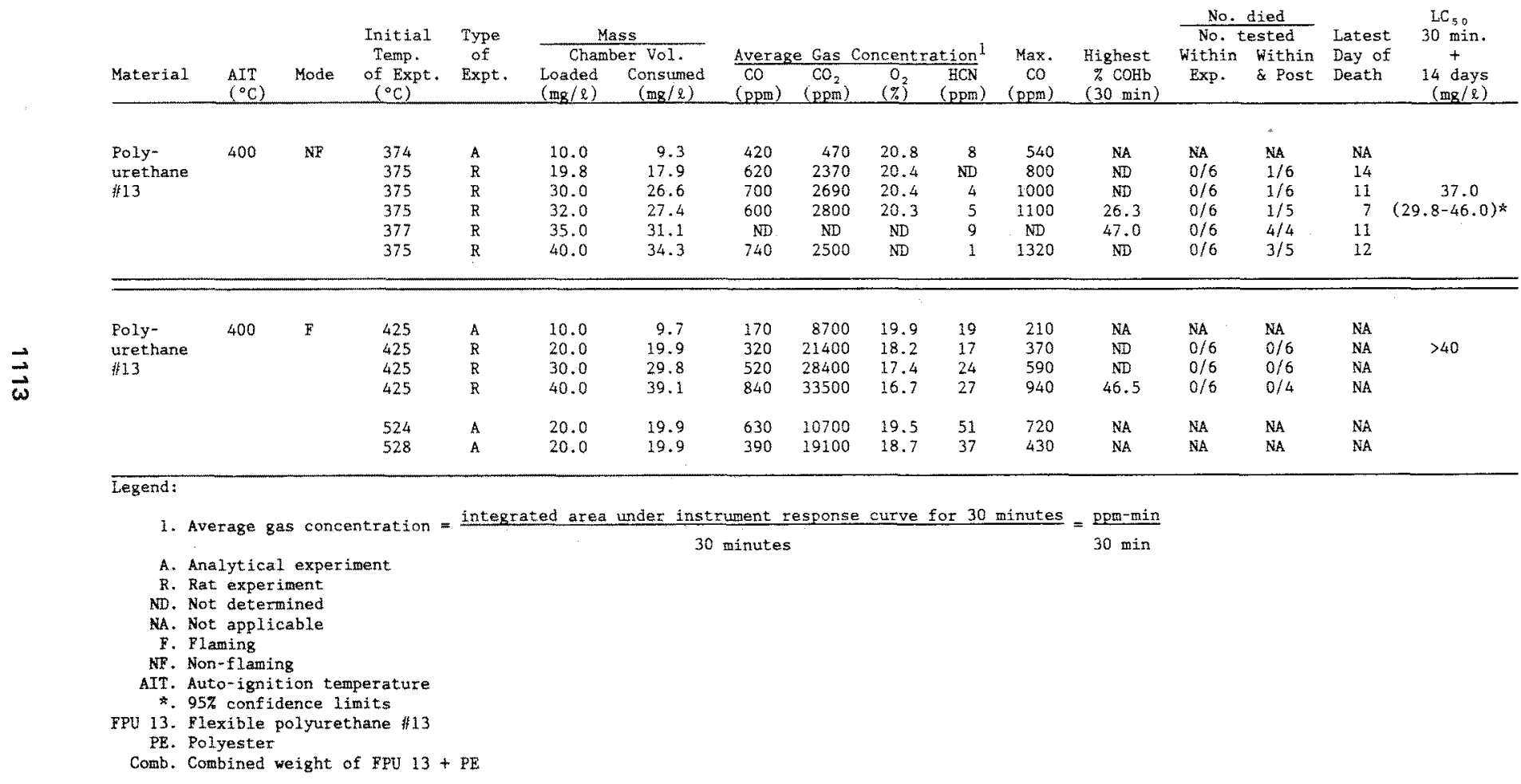


Table 2

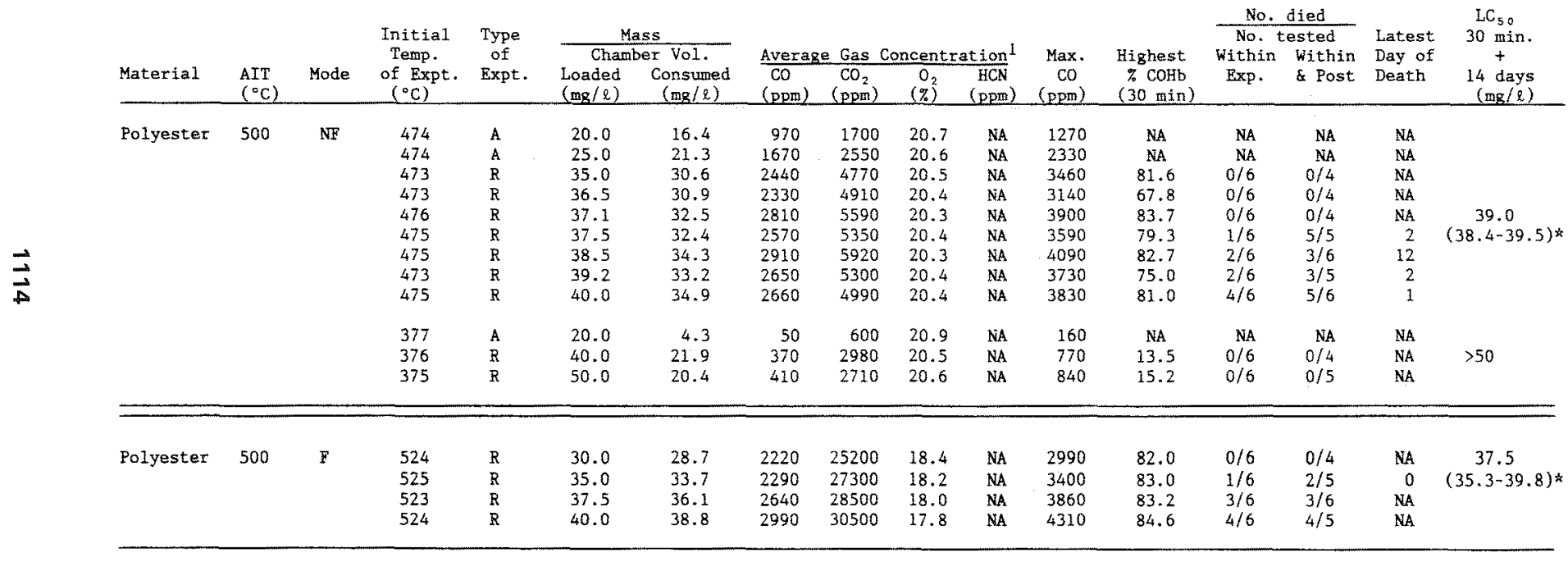

For Legend, see Table 1 
unit chamber volume (mg/e) which caused $50 \%$ of the animals to die during the 30 minute exposure plus the 14 day post-exposure observation period. (Animals that were still losing weight on day 14 were kept until they died or recovered as indicated by three days of successive weight gain. Al1 deaths were included in the $\mathrm{LC}_{50}$ calculation. Surviving cannulated animals were sacrificed following the test and only counted in the determination of the $\mathrm{LC}_{50}$ if they died during the exposure.) If no deaths occurred at the highest concentration tested, the $\mathrm{LC}_{50}$ is listed as greater than that concentration.

\section{RESULTS AND DISCUSSION}

\section{Flexible Polyurethane Foam}

The chemical and toxicological data obtained from the flexible polyurethane foam thermally decomposed under non-flaming $\left(375^{\circ} \mathrm{C}\right)$ and flaming $\left(425^{\circ} \mathrm{C}\right.$ and $\left.525^{\circ} \mathrm{C}\right)$ conditions are presented in table 1. Similar to other non-fire retarded flexible polyurethane foams tested in this laboratory, no animal deaths occurred during the 30 minute exposures to concentrations up to $40 \mathrm{mg} / \mathrm{l}$ regardless of the mode of decomposition $[5,6]$. Post-exposure deaths only occurred following the nonflaming experiments. The $\mathrm{LC}_{50}$ value for the non-flaming mode was $37.0 \mathrm{mg} / \mathrm{l}$ with $95 \%$ confidence limits of $29.8-46.0 \mathrm{mg} / \mathrm{l}$, whereas, the $\mathrm{LC}_{50}$ value for the $\mathrm{flaming}$ mode was greater than $40 \mathrm{mg} / \mathrm{l}$, i.e., no animal deaths were noted from any of the concentrations tested up to $40 \mathrm{mg} / \mathrm{l}$.

Recent results [11] from this laboratory on the toxicity of $\mathrm{CO}, \mathrm{CO}_{2}$ and $\mathrm{HCN}$ alone and in various combinations have shown that the 30 minute $L_{50}$ for $C O$ in air was $4600 \mathrm{ppm}$. No animals died below $4100 \mathrm{ppm}$ or post-exposure. The 30 minute $\mathrm{LC}_{50}$ for $\mathrm{CO}_{2}$ in air was greater than $18 \%(1 \%=10,000 \mathrm{ppm})$. However, when $\mathrm{CO}$ and $\mathrm{CO}_{2}$ were combined, the presence of $5 \% \mathrm{CO}_{2}$ increased the toxicity of $\mathrm{CO}$ such that animals died from 30 minute exposures to $2500 \mathrm{ppm}$. Some of these deaths were within 24 hours. The combination of $\mathrm{CO}$ and $\mathrm{HCN}$ ( 30 minute $\mathrm{HCN}^{\mathrm{L}} \mathrm{LC}_{50}=160 \mathrm{ppm}$ ) showed the following additive effect:

If $\frac{[\mathrm{CO}]}{\mathrm{LC}_{50} \mathrm{CO}}+\frac{[\mathrm{HCN}]}{\mathrm{LC}_{50} \mathrm{HCN}} \geq 1$, the animals died.

When this formula equalled less than 1, the animals lived. Again deaths were observed up to 24 hours post-exposure.

Comparison of the gas concentrations generated from the polyurethane experiments to the pure gas experiments quoted above showed that lethal amounts were not produced in any of the tests (Table 1). Therefore, the deaths, which occurred as late as 14 days in the non-flaming mode, were due to other toxic combustion products or undetermined factor $(s)$.

\section{Polyester}

A11 the chemical and toxicological data collected from the thermal degradation of polyester are shown in table 2 . In the non-flaming mode at $475^{\circ} \mathrm{C}$, the $\mathrm{LC}_{50}$ value of the polyester was $39.0 \mathrm{mg} / \mathrm{l}$ with $95 \%$ confidence 1 imits of $38.4-39.5 \mathrm{mg} / \mathrm{l}$. Animal deaths were noted both during and following the 30 minute exposures. At $375^{\circ} \mathrm{C}$, however, no animal deaths were observed up to concentrations of $50 \mathrm{mg} / \mathrm{l}$. However, it is important to note that at the lower temperature $\left(375^{\circ} \mathrm{C}\right)$, only $22-$ $55 \%$ of the original sample was consuned; whereas, at $475^{\circ} \mathrm{C}$, approximately $85 \%$ of the sample was consumed. Based upon a comparison of the toxicological effects at the actual masses consumed at $475^{\circ} \mathrm{C}$, deaths would not be expected at the masses consumed at the lower temperature. 
Examination and comparison of the gas concentrations that were generated during these non-flaming experiments with our pure and combined gas toxicity experiments discussed above indicate that the average Co levels are 37-80\% lower than that necessary to cause death by $\mathrm{CO}$ alone. In many experiments, the CO levels did not plateau but continued to rise throughout the exposures reaching a maximum at 30 minutes. This maximum value, however, was sti11 lower than the 30 minute $L_{50}$ value for $\mathrm{CO}$ in air $\left(4600 \mathrm{ppm}\right.$ ) (Table 2). The average $\mathrm{CO}_{2}$ present is about $10 \%$ of that necessary to increase the susceptibility of the rats to lower levels of $\mathrm{CO}$. However, the maximum $\mathrm{COHb}$ levels at the end of these 30 minute lethal exposures are relatively high, 75-83\%. These results indicate that $\mathrm{CO}$, although low, is contributing to the within-exposure deaths, but other toxic or irritant gas(es) are also acting in conjunction with or to potentiate the effects of the CO. The cause of the late post-exposure deaths are unexplained.

In the flaming mode, the $\mathrm{LC}_{50}$ value for the polyester was $37.5 \mathrm{mg} / \mathrm{l}$ with $95 \%$ confidence levels of $35.3-39.8 \mathrm{mg} / \mathrm{\ell}$ (Table 2 ). In the lethal experiments, the $\mathrm{COHb}$ levels ranged from $83-85 \%$ and the rats died within exposure or shortly thereafter. These factors would implicate $\mathrm{CO}$ as the main toxicant. However, the average $\mathrm{CO}$ is approximately $50-65 \%$ of the lethal concentration determined for $\mathrm{CO}$ alone. Even considering the effect of $\mathrm{CO}_{2}$ on $\mathrm{CO}$, the average values of $\mathrm{CO}$ and $\mathrm{CO}_{z}$ from flaming polyester are still too low to account for the deaths that occurred during these 30 minute exposures. Only if one considers the maximum co levels along with the $\mathrm{CO}_{2}$ concentrations would the deaths be predictable.

\section{Combined Flexible Polyurethane Foam and Polyester}

Non-flaming experiments. The thermal decomposition of both flexible polyurethane foam and polyester in the non-flaming mode was studied at $375^{\circ} \mathrm{C}$ which was $25^{\circ} \mathrm{C}$ below the autoignition temperatures of the polyurethane. In these experiments, the polyester fabric was folded and dropped into the cup furnace immediately preceding the polyurethane foam. Upon heating, the samples collapsed in less than one minute and formed a black ball in approximately two minutes.

Since the polyester, by itself, was not toxic at $375^{\circ} \mathrm{C}^{2}$ even at the highest loading tested $(50 \mathrm{mg} / \mathrm{l})$, a sublethal amount of polyester $(20 \mathrm{mg} / \ell)$ was chosen to test whether this addition would increase the toxicity (lethality) of the polyurethane foam in the combination experiments. If the polyester component has no effect at this temperatures, then the addition of $20 \mathrm{mg} / \mathrm{l}$ of polyester to the $L_{50}$ value of the polyurethane would increase the $\mathrm{LC}_{50}$ value of the mixture by $20 \mathrm{mg} / \mathrm{l}$; that is, the $\mathrm{LC}_{50}$ value of the polyurethane, $37 \mathrm{mg} / \mathrm{l}$, would increase to approximately $57 \mathrm{mg} / \mathrm{l}$. The results, however, showed that the $\mathrm{LC}_{50}$ value of the combined materials only increased to $47.5 \mathrm{mg} / \mathrm{l}$, an indication that the polyester was not inert but contributed to the toxicity by about $10 \mathrm{mg} / 2$ (Table 3 ). The total amount of polyurethane in the combined $\mathrm{LC}_{50}$ is only $27.5 \mathrm{mg} / \ell$, which is outside the $95 \%$ confidence limits of the $\mathrm{LC}_{50}$ for polyurethane alone.

Since a significant proportion of the polyester is not decomposed at $375^{\circ} \mathrm{C}$, these data were also analyzed on the basis of mass consumed/chamber volume. The experiments on the polyester alone at $375^{\circ} \mathrm{C}$ showed that when 3.88 grams (20 $\mathrm{mg} / \mathrm{l}$ ) were loaded into the cup furnace, $78 \%$ remained as residue and only $4.3 \mathrm{mg} / \mathrm{l}$

2This lower toxicity is probably due to the large fraction (more than $45 \%$ of the initial mass loading) of the polyester which is not consumed at the lower temperature. 
Table 3

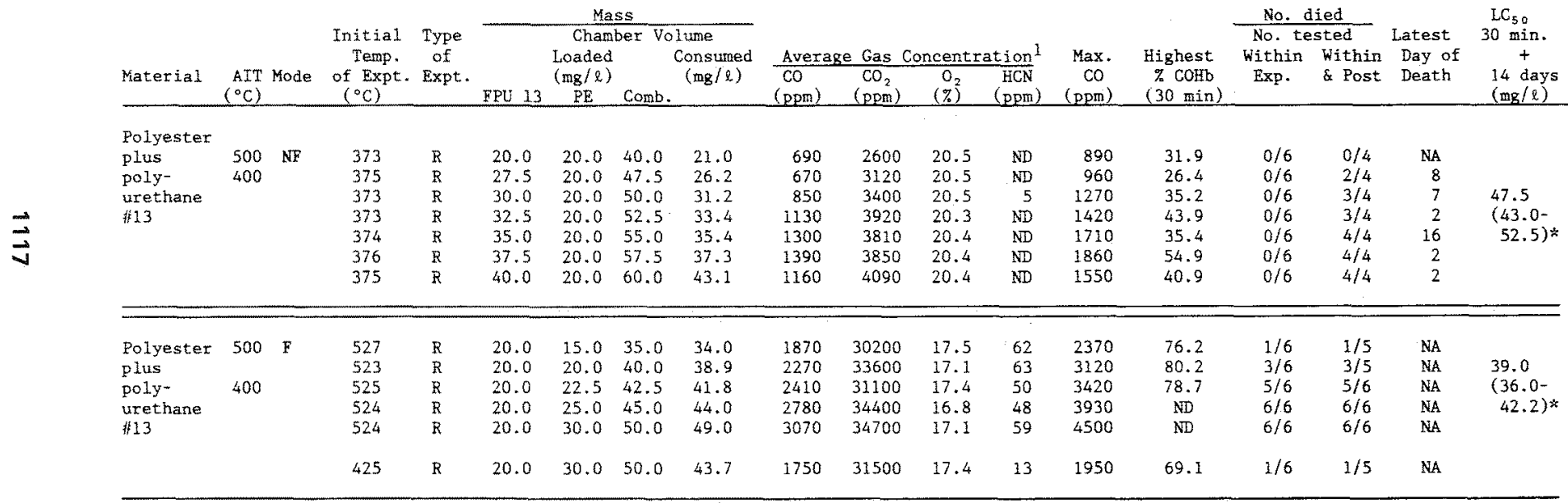

For legend, see Table 1 
were actually consumed. Using the same null hypothesis as before, that is, the polyester at this temperature has no effect on the combined toxicity, then one would expect the $\mathrm{LC}_{50}$ of the polyurethane $(31.9 \mathrm{mg} / \ell$, consumed weight) should increase by $4.3 \mathrm{mg} / \ell$ producing a combined $\mathrm{LC}_{50}$ of $36.2 \mathrm{mg} / \mathrm{l}$. However, the $\mathrm{LC}_{50}$ of the combination is only $26.2 \mathrm{mg} / l$, consumed weight, indicating that the polyester increases the toxicity by about $10 \mathrm{mg} / l_{\text {; }}$ this is the same value calculated when the mass loaded, rather than mass consumed, was considered.

In these non-flaming experiments in which $20 \mathrm{mg} / \ell$ of polyester were added to different loadings of flexible polyurethane foam, all deaths occurred during the post-exposure period. These results are more characteristic of the polyurethane experiments, decomposed by itself, and different from those seen with the polyester alone. The concentrations of measured gases ( $\mathrm{CO}, \mathrm{CO}_{2}, \mathrm{HCN}$ ) were not responsible for the post-exposure deaths that occurred.

The average concentration of the primary gases ( $\mathrm{CO}, \mathrm{CO}_{2}, \mathrm{HCN}$ ) generated from the thermal decomposition of the mixture of the materials appear to be approximately equal to the sum of the average concentrations generated from the individual materials under non-flaming conditions (Table 4 and Figure 1). Therefore, if the concentrations of the primary gases from the thermal decomposition of the individual components are known, then a reasonable prediction of the gas concentrations from the mixture decomposed under the same conditions can be made.

Flaming experiments. The experiments in which the flexible polyurethane foam and polyester were combined and tested in the flaming mode were conducted at $525^{\circ} \mathrm{C}$ $\left(25^{\circ} \mathrm{C}\right.$ above the autoignition temperature of the polyester) to ensure that both materials would flame. In these experiments, the mass concentration of polyurethane was kept constant at $20 \mathrm{mg} / \mathrm{l}$ and only that of the polyester was varied (Table 3). The reason for this approach was to see if a non-lethal amount of the less toxic material (in this case, the polyurethane foam) would increase the toxicity of the polyester whose $\mathrm{LC}_{50}$ could be measured. The polyurethane foam when tested by itself in the flaming mode at $425^{\circ} \mathrm{C}$ had produced no deaths either during or post-exposure at concentrations up to $40 \mathrm{mg} / \ell$, whereas, the polyester fabric when decomposed by itself in the flaming mode at $525^{\circ} \mathrm{C}$ had produced both within and post-exposure deaths. The $\mathrm{LC}_{50}$ value for the flaming polyester fabric by itself was $37.5 \mathrm{mg} / \mathrm{l}$. Therefore, if the polyurethane was toxicologically inert, the addition of $20 \mathrm{mg} / \mathrm{l}$ of polyurethane should have raised the $\mathrm{LC}_{50}$ value to $57.5 \mathrm{mg} / \mathrm{\ell}$. In actuality, the 30 minute and 14 day $\mathrm{LC}_{50}$ value calculated for the combined exposures was $39.0 \mathrm{mg} / \ell$ with $95 \%$ confidence limits of $36.0-42.2$ $\mathrm{mg} / \mathrm{l}$. These results, showing that the $\mathrm{LC}_{50}$ value for the combined materials was lower than expected by almost the exact amount of polyurethane added to the system, are an indication that the polyurethane and the polyester are both contributing in an additive manner to the toxicity. In other words, the combination of $19 \mathrm{mg} / \mathrm{l}$ of polyester and $20 \mathrm{mg} / \mathrm{l}$ of polyurethane produced the $\mathrm{LC}_{50}$; whereas, $20 \mathrm{mg} / \mathrm{l}$ of the polyurethane foam decomposed by itself in the flaming mode produced no deaths (Table 1) and the polyester decomposed by itself did not produce any deaths below a concentration of $35 \mathrm{mg} / \ell$ (Table 2 ). Thus individual sublethal concentrations of this polyurethane foam and polyester fabric are adding up to a concentration which is lethal.

Examination of the average gas concentrations of $\mathrm{CO}, \mathrm{CO}_{2}$, and $\mathrm{HCN}$ which were generated during these exposures and comparison of these gas values with our pure gas toxicological studies shows that the concentrations of these gases were sufficient to account for the deaths that occurred. Table 3 also shows HCN levels higher than those seen in the flaming exposures of polyurethane alone at $525^{\circ} \mathrm{C}$ which, in turn, were greater than at $425^{\circ} \mathrm{C}$ (Table 1). Figure 2 shows the 
generation of HCN from $20 \mathrm{mg} / \ell$ of the flexible polyurethane when decomposed alone or combined with the polyester under various flaming conditions. Polyurethane decomposed alone at $425^{\circ} \mathrm{C}$ produced an average HCN concentration of $19 \mathrm{ppm}$; whereas, at $525^{\circ} \mathrm{C}$, it produced an average of $37 \mathrm{ppm}$ in one experiment and $51 \mathrm{ppm}$ in another. The flaming decomposition of various amounts of polyester with 20 $\mathrm{mg} / \mathrm{l}$ of polyurethane at $525^{\circ} \mathrm{C}$ produced greater concentrations of HCN than in any of the experiments on the polyurethane alone (Tables 1,3 and Fig. 2). This result was unexpected since polyester contains no nitrogen and should not contribute to the HCN generation. Figure 2 also shows that the HCN generation over time from $20 \mathrm{mg} / \ell$ of flaming polyurethane foam alone tends to plateau during the 30 minute test, whereas, in the combination studies of this polyurethane $(20 \mathrm{mg} / \mathrm{l})$ and polyester, the HCN continues to increase throughout the experiments. The reason for this increased level of $\mathrm{HCN}$ is unexplained at this time.

Table 4

Gas Concentrations from the Thermal decomposition of Polyurethane Foam and Polyester Alone and in Combination

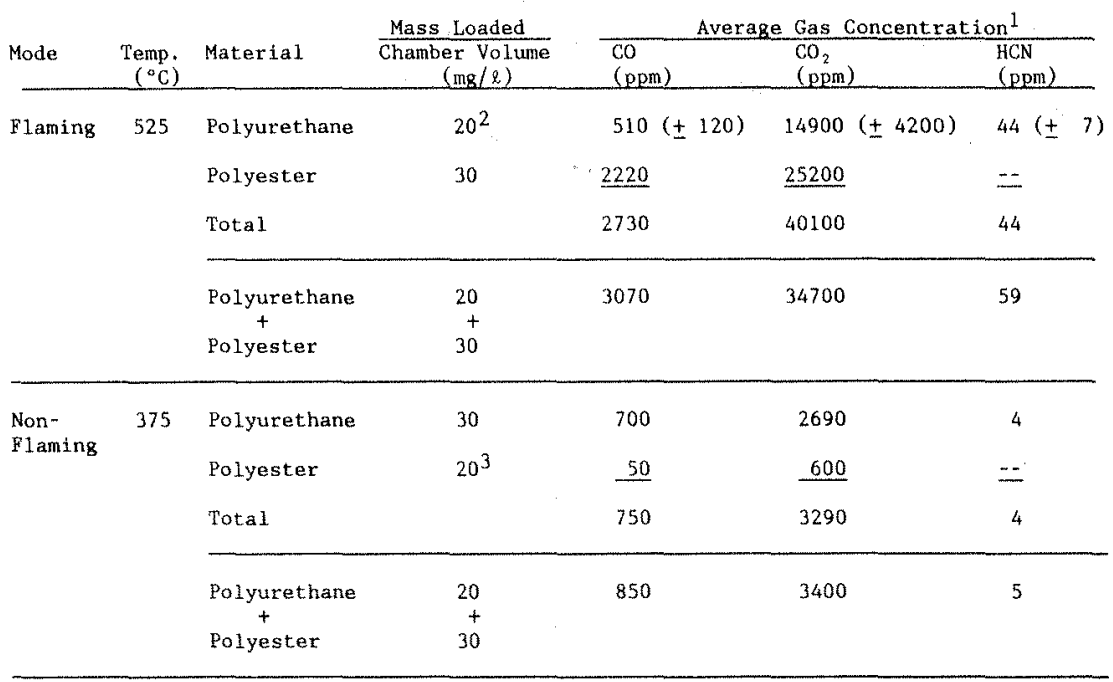

1 Average gas concentration: $\frac{\text { integrated area under instrument response curve for } 30 \text { minutes }}{30 \text { minutes }}=\frac{\mathrm{ppm}-\mathrm{min}}{30 \mathrm{~min}}$

2 Results are average \pm range of two analytical experiments

3 Analytical experiment (no animals) 


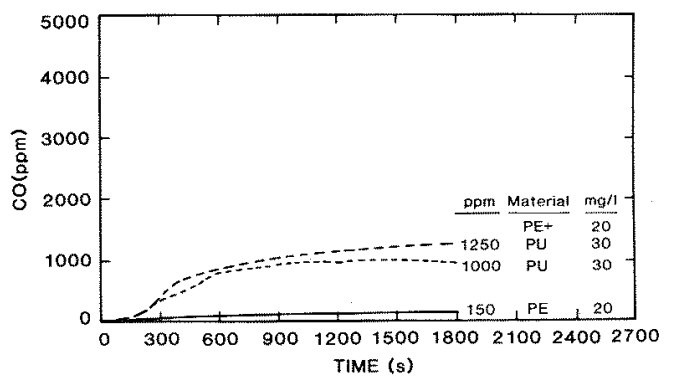

Figure 1. Co Generation from Flexible Polyurethane Foam and Polyester Decomposed Alone and Together. Non-Flaming $375^{\circ} \mathrm{C}$.

$\overrightarrow{\vec{U}}$

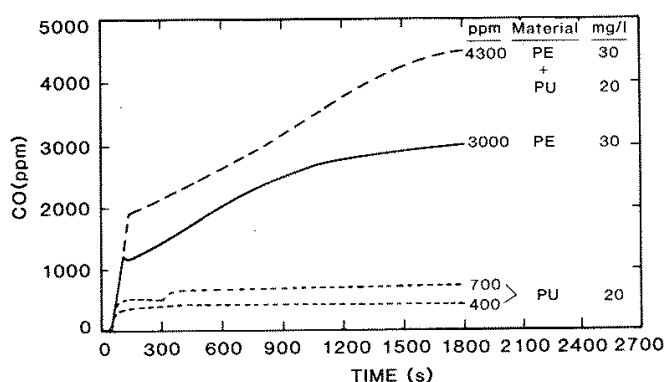

Figure 3. Co Generation from Flexible Polyurethane Foam and Polyester Decomposed Alone and Together. Flaming $525^{\circ} \mathrm{C}$.

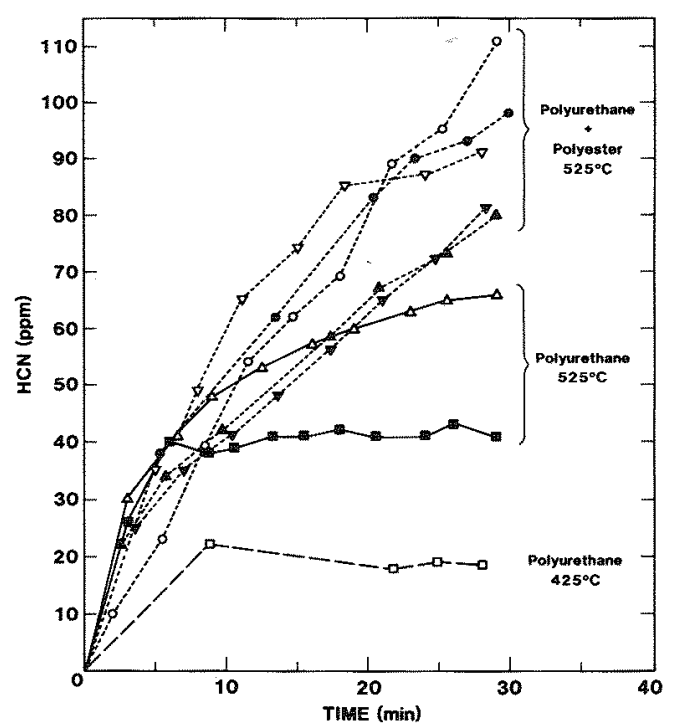

Figure 2. Generation of HCN from $20 \mathrm{mg} / \mathrm{l}$ of Polyurethane Decomposed Alone and with Different Amounts of Polyester Under Flaming Conditions. 
In the flaming mode, the concentrations of CO from combined materials was also greater than the sum of the CO concentrations from the individual materials (Figure 3). This was more apparent from the graphic representation of the actual generation of $\mathrm{CO}$ than from the tabular depiction of the average concentrations (Table 4).

\section{CONCLUSIONS}

\section{Individual Materials}

- The decomposition products of the flexible polyurethane foam produced no deaths during exposure and only caused post-exposure deaths in the nonflaming mode.

- The polyester when decomposed $25^{\circ} \mathrm{C}$ above or below its autoignition temperature caused deaths both during and following exposures.

- Comparison of the $\mathrm{CO}, \mathrm{CO}_{2}$, and $\mathrm{HCN}$ concentrations generated from the individual materials with pure gas toxicity experiments (performed with single and multiple gases) indicated:

1. the deaths from flexible polyurethane could not be explained by the concentrations of these gases,

2. non-flaming polyester produced relatively high $\mathrm{COHb}$ (75-83\%) levels, but lower than lethal average or maximum $\mathrm{CO}$ concentrations. Even when $\mathrm{CO}$ was considered with $\mathrm{CO}_{2}$ (which potentiates the toxicity of $\mathrm{CO})$, the combination was not sufficient to account for the deaths, and

3. the deaths from exposures to flaming polyester products were probably due to $\mathrm{CO}$ since $\mathrm{COHb}$ values were $83-85 \%$. In this case, the maximum (not the average) concentrations of $\mathrm{CO}$ plus $\mathrm{CO}_{2}$ were sufficient to predict the deaths.

\section{Combined Materials}

- Depending on the amount thermally decomposed, both materials contributed to the combined toxicity. In the flaming mode, the contribution was additive.

- Similar to the polyurethane results, the non-flaming combined experiments only produced post-exposure deaths which were not attributable to the generated $\mathrm{CO}, \mathrm{CO}_{2}$, and $\mathrm{HCN}$ concentrations.

- The deaths observed from the flaming combined experiments were explainable based on the concentrations of $\mathrm{CO}, \mathrm{CO}_{2}$, and $\mathrm{HCN}$.

- Comparison of the gas concentrations from the combined materials to those from the individual materials indicated:

1. The non-flaming generation of $\mathrm{CO}, \mathrm{CO}_{2}$, and $\mathrm{HCN}$ appear to be approximately equal to the sum of the concentrations from the single materials. 
2. The flaming generations of $\mathrm{CO}$ and $\mathrm{HCN}$ were greater than the sum of those from the single materials.

\section{ACKNOWLEDGEMENTS}

This work was supported in part by the Consumer Product Safety Commission, Washington, DC, Dr. Rita Orze1, Project Officer. The conclusions are those of the authors and not the Consumer Product Safety Commission.

\section{REFERENCES}

1. Fire in the United States, Second Edition, Federal Emergency Management Agency, FEMA-22, July, 1982.

2. "Literature Review of the Combustion Toxicity of Flexible Polyurethane Foam," Status Report on Fire Combustion Toxicity, TAB-B. Consumer Product Safety Commission, Washington, DC 20207, May 31, 1984, 103 p.

3. Braun, E. and Levin, B.C.: "Polyesters: A Review of the Literature on Products of Combustion and Toxicity," Nat. Bur. Stand. (U.S.) Gaithersburg, MD, NBSIR 85-3139, June 1985.

4. Alarie, Y., Stock, M.F., Matijak-Schaper, M., and Birky, M.M.: "Toxicity of Smoke During Chair Smoldering Tests and Sma11 Scale Tests Using the Same Materials," Fund. \& Appl. Tox. 3:619-626, 1983.

5. Levin, B.C., Paabo, M., Fultz, M.L., Bailey, C., Yin, W., and Harris, S.E.: "An Acute Inhalation Toxicological Evaluation of Combustion Products from Fire Retarded and Non-Fire Retarded Flexible Polyurethane Foam and Polyester," Nat. Bur. Stand. (U.S.) Gaithersburg, MD, NBSIR 83-2791, November, 1983.

6. Levin, B.C., Fowe11, A.J., Birky, M.M., Paabo, M., Stolte, A., and Malek, D.: "Further Development of a Test Method for the Assessment of the Acute Inhalation Toxicity of Combustion Products," Nat. Bur. Stand. (U.S.) Gaithersburg, MD, NBSIR 82-2532, June 1982.

7. Paabo, M., Birky, M.M., and Womble, S.E.: "Analysis of Hydrogen Cyanide in Fire Environments," J. Comb. Tox. 6:99-108, 1979.

8. Committee on Care and Use of Laboratory Animals: "Guide for the Care and Use of Laboratory Animals," DHEW publication No. (NIH) 78-23. U.S. Dept. of HEW, Public Health Service, National Institutes of Health, 1978 .

9. Packham, S.C., Frens, D.B., McCandless, J.B., Patajan, J.H., and Birky, M.M.: "A Chronic Intra-arterial Cannula and Rapid Technique for Carboxyhemoglobin Determination," J. Comb. Tox. 3:471-478, 1976.

10. Litchfield, J.T., Jr., and Wilcoxon, F.: "A Simplified Method of Evaluating Dose-effect Experiments," J. Pharmacol. and Exp. Therapeut. 96: $99-113,1949$.

11. Levin, B.C., Paabo, M., Gurman, J.L., Harris, S.E., and Bailey, C.S.: "Toxicological Effects of the Interactions of Fire Gases and Their Use in a Hazard Assessment Computer Mode1," The Toxicologist, 5:127, 1985. 